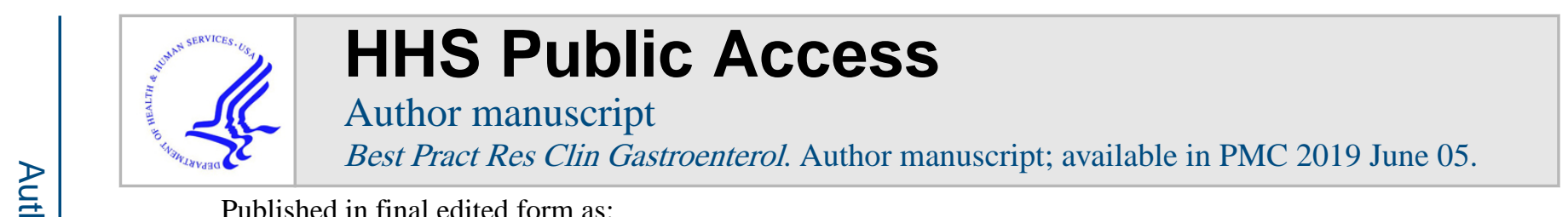

Published in final edited form as:

Best Pract Res Clin Gastroenterol. 2017 June ; 31(3): 311-320. doi:10.1016/j.bpg.2017.06.002.

\title{
Management of hepatitis B in special populations
}

\author{
Kali Zhou and Norah Terrault ${ }^{*}$ \\ Division of Gastroenterology/Hepatology, University of California San Francisco, USA
}

\begin{abstract}
Special populations infected with chronic HBV include those with decompensated cirrhosis, coinfections (HIV, HCV, HDV), hemodialysis and renal failure, immunosuppressed including transplant patients, children and women in pregnancy. These populations differ in their natural history and risk for liver-related complications, the indications for anti-HBV therapy as well as the recommendations regarding the HBV drugs used, duration of therapy and anticipated endpoints. Reflecting the special populations with substantive changes in management in recent years, this review focuses on HBV-HIV coinfected patients, immunosuppressed patients at risk for reactivation, liver transplant recipients and pregnant women. Management of women in the context of pregnancy and post-partum requires consideration of risks to mother and fetus/infant, including the risk of mother-to-child transmission. HBV-HIV coinfected patients require initiation of treatment concurrent with their HIV therapy and the HBV drugs used must by selected to minimize HIV and HBV resistance long-term. Increasing recognition of the risk for HBV reactivation with immunosuppressive therapy has led to recommendations to use prophylactic HBV therapy in patients with moderate to high risk of reactivation. Liver transplant recipients with HBV require life-long therapy to prevent or treat HBV infection but with current therapies, graft and patient survival are excellent.
\end{abstract}

\section{Summary}

Important advances in the management of special populations have been made in recent years, reflecting and improved understanding of when and how to use highly effective and safe antiviral therapies, such as entecavir and/or tenofovir (disoproxil fumarate or alafenamide formulations) to achieve desired outcomes.

\section{Keywords}

Pregnancy; HBV-HIV coinfection; Reactivation; Transplantation; Tenofovir; Entecavir; Nucleos(t)ide analogues

The natural history of chronic hepatitis B, risk for disease progression and liver-related complications can be altered by coexisting conditions or comorbidities. These "special populations" include those with decompensated cirrhosis, coinfections with hepatitis viruses

\footnotetext{
*Corresponding author. University of California, San Francisco, S357, 513 Parnassus Ave. San Francisco, California 94143-0538, USA.

Conflict of interest statement

KZ reports grant support from T32 DK060414. NT reports grant support from Gilead Sciences and BMS.
} 
or HIV, renal failure, immunosuppressed status including solid organ and stem cell transplant recipients, children and pregnant women. For these patient groups, the recommendations for treatment typically differ from those of the "standard" patient with chronic hepatitis B. Some of these special populations are reviewed in other sections (cirrhosis, hepatitis D virus). Here, we focus on those populations for whom indications for treatment and/or recommendations regarding specific drugs for treatment have recently occurred - specifically pregnant women, those with HIV coinfection, those receiving immunosuppressive therapy and liver transplant recipients.

\section{HBV and pregnancy}

\section{Screening of pregnant women}

Perinatal transmission is estimated to account for $50 \%$ of the global burden of chronic hepatitis B, and in endemic areas is the prime mode of perpetuating hepatitis B infection in the population [1]. Exposure to maternal blood or other secretions at the time of delivery is the primary risk with in utero transmission rare. Pregnancy-associated procedures such as amniocentesis may be an additional risk factor if maternal HBV DNA levels are high [2]. Infants exposed to hepatitis B have a high likelihood of developing chronic infection but combined active-passive immunoprophylaxis of infants reduces the rate of perinatallyacquired HBV from $90 \%$ to $10-30 \%$ [3]. For this reason, screening of all pregnant women is recommended with infants of $\mathrm{HBsAg}$ positive mothers provided active-passive prophylaxis [4]. The first dose of hepatitis B vaccine and HBIG should be administered within $12 \mathrm{~h}$ of birth, as delays increase the likelihood of prophylaxis failure. The WHO also recommends that women who are HBsAg positive have testing for hepatitis D virus (HDV). This has relevance primarily in management of the mothers, as the risk of perinatal transmission of HDV is low and active-passive prophylaxis for HBV will protect infants from HDV infection.

\section{Natural history of HBV in pregnancy}

Pregnancy is a unique immunologic period with immunologic tolerance to paternally derived fetal antigens resulting in altered immune responses at the maternal-fetal interface (i.e. the placenta) as well as at the systemic level. Alanine aminotransferase (ALT) levels tend to be lower in the second and third trimester compared to first trimester [5]. HBV flares during pregnancy are infrequent. In a longitudinal study of US women who were not on antiviral therapy pre-pregnancy, only $6 \%$ experienced a $\geq 2-\log$ increase in HBV DNA during pregnancy accompanied by ALT flares [6]. For women on antiviral therapy pre-pregnancy who stop treatment when pregnancy is diagnosed, viral rebound with ALT flare appears to occur more frequently (67\% in one study) followed by spontaneous recovery in the vast majority [7].

Post-partum ALT flares are reported in $9-45 \%$ of women, mostly within 3 months of delivery $[5,8,9]$. The majority of flares were subclinical - although there are rare reports of hepatic decompensation, likely in women who had advanced fibrosis during pregnancy. Whether HBV DNA levels predict risk of flares is unclear [6,10]. The frequency of flares in women who stopped antivirals at or soon after delivery appears similar or slightly higher 
than women not treated with antivirals during pregnancy [11]. Continuation of antiviral therapy post-partum does not prevent flares $[6,11]$ and most flares resolve without intervention.

\section{Treatment considerations in women of child-bearing age}

Antiviral drugs and safety in pregnancy-Three drugs have been studied widely and are recommended during pregnancy - tenofovir, telbivudine (LdT) or lamivudine (LMV) [12]. Using the prior (to 2015) FDA designation for drug safety in pregnancy, LdT and tenofovir are pregnancy class $\mathrm{B}$ agents, indicating available animal studies do not identify teratogenic effects. $\mathrm{LMV}$ is a class $\mathrm{C}$ agent, based on some first trimester teratogenic effects in rabbits, but there is substantial human data supporting its safety in pregnancy. Of the three options, only tenofovir should be used as it is associated with lowest risk of viral resistance in women needing continuous therapy. Importantly, the published experience is with tenofovir disoproxil fumarate (TDF). The safety of the new formulation, tenofovir alafenamide (TAF) has not been assessed in pregnancy, though studies in HIV-HBV infected women are ongoing.

Since the risk period for teratogenicity is primarily the first trimester, minimizing exposures to non-recommended antivirals during the first trimester should be the goal. The Antiretroviral Pregnancy Registry is an international voluntary, drug exposure-registration registry of congenital malformations in infants of women exposed to antiretrovirals and antivirals in pregnancy. In the most recent analysis, 12,499 women were exposed to LMV, 4837 to TDF, 9 to LdT and 3 to TAF. The rate of birth defects among women with first trimester exposures was 3.06\% (95\% CI 2.60-3.62) for LMV and 2.23\% (95\% CI: $1.73-$ $2.83 \%$ ) for TDF, which is similar to that of general population at $3 \%$ [13]. A recent systematic review, which included mostly women exposed to LMV and TDF, found no significant differences in the congenital malformation rate, prematurity rate, and Apgar scores in women receiving antivirals during pregnancy versus untreated controls [14].

There has been concern regarding the effects of longer-term exposures to TDF on infant bone mineral density and bone growth. As most studies were conducted in TDF-exposed infants of HIV-infected mothers, it is unclear how accurately these findings translate to TDFexposed infants of HBV-infected mothers [15-19]. Further, whether TAF can mitigate any potential risk to infant bone health is unknown at this time.

Pre-pregnancy planning and HBV therapy-The criteria to initiate antiviral therapy in women of childbearing age are the same as any person with chronic hepatitis B. Women with elevated ALT levels and elevated HBV DNA levels $(>2000 \mathrm{IU} / \mathrm{mL}$ or $>20,000 \mathrm{IU} / \mathrm{mL}$ depending on $\mathrm{HBeAg}$ status) warrant consideration of antiviral therapy [12,20,21]. An assessment of disease severity is important. Women with mild disease can be deferred until after pregnancy. Those with advanced fibrosis/cirrhosis warrant treatment independent of ALT levels. In choosing therapy for women of child-bearing age, a discussion of the effects of the different antiviral drugs on a future pregnancy should be included. Peg-interferon may be an attractive option for women seeking a finite treatment course prior to starting their family. If nucleoside analogues (NAs) are used, the best option is TDF if long-term therapy 
is anticipated. ETV can be used but with the knowledge that a change of therapy to TDF should be done prior to conception.

For women on antiviral therapy who wish to stop in order to conceive, the risks of discontinuing therapy and experiencing a flare of HBV warrant careful review. Women with advanced fibrosis should be counseled to remain on antiviral therapy throughout their pregnancy and post-partum due to the concerns for decompensation in the context of an ALT flare. If antivirals are stopped, monitoring of ALT and HBV DNA levels at regular intervals (e.g. monthly) are recommended to insure HBV flares can be appropriately managed.

\section{Management of women during pregnancy}

Women on antiviral therapy who become pregnant-For women on antiviral therapy who become pregnant, discussion of the pros and cons of stopping treatment is essential. Among women who may have stopped antivirals for conception or to avoid exposures of drugs during the first trimester when risk of teratogenicity is highest, resumption of antivirals in the second trimester can be undertaken if there is strong clinical indication. For those stopping treatment, without a strong clinical indication to restart antiviral therapy during pregnancy, the HBV DNA level should be checked again at $\sim$ week 26-28 gestation to determine the need for antiviral therapy to prevent perinatal transmission (Fig. 1).

\section{Prevention of mother to child transmission in HBsAg-Positive pregnant} woman-Despite receipt of active and passive immunoprophylaxis, perinatal transmission of HBV occurs in approximately $10 \%$ of infants (up to $30 \%$ in some studies) [14]. The presence of HBeAg and high HBV DNA levels in the mother are most consistently associated with higher rates of failure of immunoprophylaxis. Invasive procedures, such as amniocentesis, may also increase the risk of perinatal transmission [22]. To prevent life-long infection in infants born to HBsAg-positive women, treatment of HBV during pregnancy needs to be considered.

Treatment with antiviral therapy in the last trimester of pregnancy is associated with a significant reduction in the risk of perinatal transmission among women with high HBV viral load [14]. Guidelines vary on the threshold used to define the women in need of treatment, with some using a higher HBV DNA level $\left(10^{6}-10^{7} \mathrm{I} / \mathrm{mL}\right)[20,21,23]$. Metaanalyses evaluating mother-to-child transmission and viral load thresholds support the importance of having HBV DNA levels less than $200,000 \mathrm{IU} / \mathrm{mL}$ at delivery $[14,24]$. In a study of 869 infant-mother pairs and 27 infected infants, the frequency of immunoprophylaxis failure by pre-delivery HBV DNA was $0 \%$ for HBV DNA levels $<10^{6}$ $(<200,000 \mathrm{IU} / \mathrm{mL}), 3.2 \%$ for levels of $10^{6-6.99}(200,000-2$ million IU/mL), $6.7 \%$ for levels between $10^{7-7.99}$ (2-20 million IU/mL) and 7.6\% for HBV DNA levels $10^{8}$ copies $/ \mathrm{mL}$ (>20 million IU/mL) [25]. Among 200 Chinese mothers, HBeAg positive with HBV DNA $>200,000 \mathrm{IU} / \mathrm{mL}$ randomized to TDF $300 \mathrm{mg}$ daily starting at week 30-32 versus no antiviral therapy and with all infants given immunoprophylaxis, the rates of perinatal transmission were reduced from $18 \%$ to $5 \%$ on intent to treat analysis $(\mathrm{P}=0.007)$ and from $7 \%$ to $0 \%(\mathrm{P}=0.01)$ on per-protocol basis [26]. A recent systematic review concluded that 
use of TDF, LMV or LdT appeared to be safe in pregnancy with no increase in adverse maternal or fetal outcomes [14]. Guidelines recommend starting antiviral therapy between weeks 28-32 but for women with very high HBV DNA levels, starting treatment earlier (in the second trimester) may be necessary to achieve a HBV DNA $<200,000 \mathrm{IU} / \mathrm{mL}$ at delivery. Pregnant women starting antiviral treatment at weeks 28-32 gestation should continue to the time of delivery or post-partum week 4 [12,20,21,23] (Fig. 1).

The use of antiviral prophylaxis is cost-saving $[27,28]$. Using US-based healthcare costs, the additional of antiviral prophylaxis to current recommendations for immunoprophylaxis for infants yielded 489 fewer cases of chronic hepatitis B in newborns, 800 quality-adjusted life years and \$2.8 million in cost-savings [27], reflecting the low cost of short duration antiviral therapy in pregnant women with high HBV-DNA load versus the high lifetime cost of caring for persons with chronic hepatitis B.

Delivery and post-partum management-There are insufficient data to advise on the mode of delivery. In a study of $492 \mathrm{HBsAg}$-positive women, the risk of perinatal transmission was lowest with elective caesarian section (1.4\%) compared to those with vaginal delivery $(3.4 \%, \mathrm{p}<0.032)$ or urgent caesarian section $(4.2 \%, \mathrm{p}<0.02)$ [29]. In an analysis adjusted for HBV DNA level at delivery, urgent caesarian section (vs elective or vaginal delivery) conferred the highest risk of mother-to-child transmission (OR 4.3, 95\% CI 1.9 - 9.8). Importantly, there were no transmission events among mothers with pre-delivery HBV DNA levels under 200,000 IU/mL, regardless of mode of delivery [29].

Breastfeeding is not contraindicated [12,21]. Breastfeeding does not increase the risk of perinatal transmission in infants who receive immunoprophylaxis. Women on antiviral therapy likely have very low titers of drug metabolites in their breast milk, but exposures are minimal [30,31]. For women taking antivirals only to prevent perinatal transmission, the antiviral drug can be stopped at the time of delivery. For women with indications for antiviral therapy due to active HBV disease, the decision to stop antivirals during the period of breastfeeding should take into consideration the risk of ALT flares and disease progression in the absence of treatment.

\section{HBV/HIV coinfection}

\section{Epidemiology}

Coinfection with chronic hepatitis B infection is frequently seen in patients with human immunodeficiency virus (HIV) due to shared routes of transmission. In the United States and Europe, considered regions with low HBV endemicity, approximately 7-10\% of patients with HIV have evidence of chronic HBV infection, which represents a 10-20-fold higher prevalence than in the HIV negative population [32,33]. Both infections are typically acquired in adolescence or adulthood. Despite increased availability and awareness of the HBV vaccine, prevalence rates of coinfection in an outpatient HIV cohort in the US remained constant from 1996 to 2007 [32]. In this same cohort, coinfection was more common in men than women, in men who have sex with men compared to injection drug users or high-risk heterosexuals [32]. 
Regions with high HBV endemicity such as Asia and Africa have higher rates of coinfection estimated between 20 and $30 \%$ of all HIV-positive patients. HBV is typically acquired perinatally or in early childhood, with HBV infection often preceding HIV infection by decades [34]. Adult transmission of HBV is much less common, even in those with high-risk sexual behaviors, due to high rates of prior exposure and chronic infection [35]. As such, perinatal vaccination for $\mathrm{HBV}$ has the potential to significantly impact rates of coinfection in these regions. In Taiwan, after institution of a nationwide HBV vaccination scheme in 1984, the rate of HBsAg seroprevalence in HIV positive patients decreased from $20.3 \%$ to $3.3 \%$ [36].

\section{Natural history}

HIV patients are at higher risk of developing chronic HBV infection after acute infection with early studies showing that coinfected patients were slower to clear hepatitis B e antigen and on average had higher HBV DNA levels compared to HBV monoinfected patients [37]. Coinfection with HIV is associated with accelerated fibrosis progression and increased risk of cirrhosis, decompensation and liver-related deaths [34]. The risk of hepatocellular carcinoma (HCC) in HIV patients in the US is reported to be 4-fold higher than the general population [38], highlighting the importance of screening for $\mathrm{HCC}$ with ultrasound and alphafetoprotein at 6 month intervals in any patient who meets HCC screening criteria [39]. Compared to HIV mono-infected patients, those with HBV/HIV coinfection incur a 1.5-fold increased risk of all-cause mortality and an over 3-fold increased risk of liverspecific mortality [33]. As highly active antiretroviral therapy (ARV) has reduced HIV-related deaths, liver-related deaths have emerged as one of the leading causes of death in HIV patients [40]. Severity of immune compromise influences the natural history, as a CD4 count of less than 200 is a primary predictor of liver-related death. Lower CD4 count is also associated with increased risk of developing chronic infection, increased likelihood of HBV reactivation and anti-HBs loss, and increased rates of cirrhosis and HCC [34]. A metaanalysis of 11 studies including 12,382 patients with HBV/HIV coinfection demonstrated a pooled 1.4 times increased risk of all-cause mortality, a risk which was present both before and after institution of highly active ARV [41]. As liver-specific mortality is a major contributor to all-cause mortality, treatment of HBV to minimize liver disease progression is essential.

The effect of chronic HBV on the natural history of HIV appears to be minimal. In terms of viral and immunologic response to ARV, coinfected patients have similar time to viral suppression and rise in CD4 counts [35]. While one study reported a 2.7-fold higher incidence of AIDS-related mortality in patients with HBV-HIV coinfection [35], other studies have not seen a difference or change in the incidence of AIDS-defining illnesses among coinfected patients compared to HIV monoinfected patients [33,42].

\section{Treatment algorithms}

Current guidelines recommend all patients with HIV be started on ARV regardless of CD4 count [43]. In HIV patients with either chronic or occult HBV infection, the ARV regimen should include drugs with anti-HBV activity [44]. Cornerstones of therapy are oral nucleoside/nucleotide reverse transcriptase inhibitors (NRTI) with dual HBV and HIV anti- 
viral effect including tenofovir disoproxil fumurate (TDF) or tenofovir alafenamide (TAF), with emtricitabine (FTC) or LMV. The rationale for dual HBV therapy is to prevent development of resistance. Other HBV therapies have a limited role or are not recommended in treating coinfected patients (Table 1).

Several pre-treatment considerations exist. First, decreased renal function impacts treatment choice and baseline creatinine clearance and urinalysis should be obtained prior to treatment initiation. Any history of prior HBV treatment, such as with LMV, should be ascertained. Lastly, an assessment of liver disease stage is needed. Increasing evidence suggests noninvasive methods such as vibration-controlled transient elastography can be utilized in HIV/HBV coinfection to discriminate between mild and advanced fibrosis [45].

The recommended first-line therapy in HBV-HIV coinfection is fixed-dose TDF or TAF in combination with FTC as the backbone of an ARV regimen. Tenofovir has demonstrated potent anti-HBV effect in patients with coinfection with an excellent resistance profile [46]. It has similar efficacy in patients with and without prior LMV exposure or resistance $[46,47]$. However, TDF carries a known risk of proximal tubular injury and Fanconi syndrome, although incidence rates vary widely among studies [48]. A recent randomized controlled study has shown non-inferiority of efficacy of TAF upon switching from TDF, with lower rates of renal toxicity and bone mineral loss as potential advantages [49]. Currently, there are 3 approved fixed-dose TAF-containing combinations [1]: elvitegravir/ cobicistat/emtricitabine/TAF [2], emtricitabine/rilpivirine/TAF and [3] emtricitabine/TAF. We recommend starting with TAF/FTC-based ARV in any patient at risk of renal or bone toxicity and switching from TDF to TAF in patients who develop mild-moderate renal dysfunction or bone changes while on TDF therapy. TAF/FTC inclusive regimens are not approved for use in patients with an estimated glomerular filtration rate less than $30 \mathrm{~mL} / \mathrm{min}$. There are no documented cases of TDF/TAF resistance.

In patients with severe renal dysfunction (creatinine clearance $\$ 3 \mathrm{~mL} / \mathrm{min}$ ), ETV can be safely administered in patients on a fully suppressive ARV regimen and is preferred. A fully suppressive ARV regimen is essential since ETV has weak activity against HIV and can increase the risk of HIV resistance [50]. In patients with prior LMV resistance, emergence of ETV resistance is of concern and the ETV dose of $1 \mathrm{mg}$ should be used with close monitoring for viral breakthrough every 3 months [44].

Interferon use is associated with higher rate of adverse events and concerns regarding immunomodulatory actions [51]. However, in select patients who refuse ARV, interferon is the sole therapeutic option without risk of conferring HIV resistance. Furthermore, interferon is the only available therapy for HDV infection. Thus, while it remains an approved therapy and a consideration in patients with HBV-HIV coinfection, in practice, it is rarely used.

Other HBV antivirals such as adefovir and telbivudine are not recommended in coinfection due to lack of data, side effect profile, and/or higher rates of HBV treatment failure. In addition, development of HBV resistance is very common with LMV monotherapy and should not be used [52]. 


\section{Monitoring on treatment}

Duration of HBV treatment in HIV/HBV coinfection is indefinite. As in mono-infected patients, monitoring of HBV DNA and ALT should be performed every 3-6 months to evaluate response and monitor for potential resistance. The primary treatment endpoint is sustained suppression of HBV DNA and this is achieved in the majority of patients within 1-3 years [53,54]. Risk factors for incomplete viral suppression with tenofovir-based therapy include higher baseline HBV DNA level, presence of LMV resistance at baseline, lower CD4 counts and lower adherence [53-55]. Adherence, issues with absorption, and drug-drug interactions should be evaluated in patients with primary nonresponse and incomplete response. TDF/TAF resistance testing is not necessary as selection for tenofovir resistant mutations on therapy is exceedingly rare [56]. Monitoring of renal function should occur every 6 months for patients on TDF.

Interruption of ARV therapy in coinfected patients is to be avoided, as HBV DNA rebound is common and can lead to an exacerbation of liver disease. If HIV virologic failure requires a modification of ARV, the ARV drugs that have activity against HBV should be continued with other suitable ARV drugs for HIV suppressive added. If an ARV interruption is needed, close monitoring of HBV DNA levels is recommended with resumption of an appropriate and effective ARV regimen as soon as possible [44].

\section{HBV in the setting of immunosuppression}

Experts recommend testing patients at risk for HBV who are undergoing immunosuppressive therapies. In countries with intermediate or high prevalence of HBV, screening all patients may be considered. Testing should include HBsAg, anti-HBc and antiHBs. Those without markers of HBV exposure, can be offered vaccination.

\section{HBV reactivation risk}

HBV reactivation in the context of immunosuppression is characterized by an initial marked increase in HBV DNA levels followed by an enhanced immune response with ALT elevation and in some cases, severe liver injury leading to decompensation and even death. The risk of reactivation varies with the serologic status of the patient and the potency of the immunosuppressive drug(s), with the highest risk group being those who receive B-cell depleting therapies such as rituximab, ofatumumab or hematopoietic stem cell transplantation (Table 2). HBV reactivation is generally less common in HBsAg-negative, anti-HBc-positive patients than $\mathrm{HBsAg}$ positive patients [57]. However, rituximabcontaining chemotherapy regimens in the late 1990s, highlighted the risk to the anti- $\mathrm{HBc}$ positive group when reports of fatal reactivation emerged [58].

Provision of prophylactic anti-HBV therapy is associated with a significant reduction in risk of reactivation [57]. For those who are $\mathrm{HBsAg}$ and/or anti-HBc positive, management of $\mathrm{HBV}$ reactivation is required. Two management strategies are employed (Table 2): (i) antiviral prophylaxis during and for 6-12 months post-treatment; or (ii) monitoring of HBV DNA levels (or HBsAg if anti-HBc positive) and institution of antiviral therapy if $\mathrm{HBV}$ 
DNA levels increase or HBsAg becomes positive. The latter is termed "on demand" therapy but requires adherence to a close monitoring schedule to be effective.

\section{Management of HBsAg positive patients}

HBsAg positive patients warrant full assessment to determine need for HBV therapy independent of the planned immunosuppressive therapy. Stage of fibrosis, $\mathrm{HBeAg}$ status, ALT levels and coinfections with HIV, HCV or HDV will influence the long-term treatment plan. For those without clinical indications for treatment, antiviral prophylaxis should be considered for those at moderate risk and routinely used for those at high risk of reactivation (Table 2). Prophylactic HBV antiviral therapy is superior to no treatment with an $\sim 85 \%$ reduction in risk of $\mathrm{HBV}$ reactivation and hepatitis flare [57]. The magnitude of the risk reduction is greatest for patients in moderate and high risk categories (Table 2), with prophylaxis resulting in 435 fewer reactivation events per 1000 persons in the high-risk group (assuming baseline rate of reactivation is 50\%) and 44 fewer reactivations per 1000 persons in the moderate risk group (assuming baseline rate of reactivation is 5\%) [57]. To minimize the risk of resistance with extended or repeated use, ETV, TDF or TAF are the preferred antiviral drugs. Treatment is started concurrent with immunosuppressive or immunomodulatory therapy and continued for 6-12 months after the last dose of treatment. For patients receiving B-cell depletion therapy or stem cell transplantation, continuing HBV antiviral treatment to 12-18 months beyond the last done of chemotherapy is prudent as late reactivation have been reported [21]. Monitoring of HBV DNA should continue for at least 6 months in low and moderate risk groups and for at least 12 months in high risk groups [59].

\section{Management of anti-HBc positive patients}

Management of patients who are HBsAg-negative and anti-HBc positive prior to starting immunosuppressive therapy is based on assessment of risk. Importantly, the presence of anti-HBs does not protect against reactivation nor influence prophylaxis decisions [60]. Expert guidance differs in assignment of risk categories. All experts classify patients receiving B-cell depleting agents as being at moderate [61] or high risk [59] and recommend prophylactic antiviral therapy. On other drug classes, there is more controversy regarding what drug class presents a moderate versus low risk of $\mathrm{HBV}$ reactivation. This is an important distinction, as patients with moderate risk should be more strongly considered for antiviral prophylaxis while those at low or very low risk can be monitored and treated "on demand".

The American Gastroenterology Association guidance classifies TNF inhibitors, other cytokine or integrin inhibitors, tyrosine kinase inhibitors, moderate (10-20 mg of prednisone or equivalent) or high-dose (>20 mg prednisone or equivalent) daily corticosteroid use for $\geq 4$ weeks, and anthracycline derivatives (e.g., doxorubicin, epirubicin) as moderate risk and azathioprine, 6-mercaptopurine and methotrexate as low risk. The American Association for the Study of Liver Diseases, in contrast, classifies daily high-dose corticosteroids (>20 mg) or anti-CD52 agent alemtuzumab as low-risk and cytotoxic chemotherapy without glucocorticoids, anti-TNF therapy, antirejection therapy for solid organ transplant, methotrexate and azathioprine as very low risk. With clinicians and patients wishing to reduce the risk of reactivation to as close to zero as possible and where concerns regarding 
HBV drug costs and side effects are not a concern, the categories outlined in Table 2 reflect the most conservative approach.

For patients in the low risk category, the "monitor and treat on demand" approach is appropriate. Antiviral therapy should be started only if HBV DNA reactivation is documented by increased HBV DNA levels or detection of HBsAg [21]. The choice of HBV agent and duration of therapy is the same as in $\mathrm{HBsAg}$ positive patients. For the treatment on demand strategy, close monitoring of HBV DNA levels and HBsAg at 1e6 month intervals during and after completion of therapy (for at least 6 months) is essential.

\section{HBV and liver transplantation}

Hepatitis B is a common indication for liver transplantation in southeast Asia but less common in North America and Europe. In many countries, the indications for liver transplantation have shifted over the past two decades to include more patients with $\mathrm{HCC}$ as the primary indication for transplant and fewer with decompensated cirrhosis [62,63]. This is believed to reflect, in part, the benefits of NA therapy in patients with advanced liver disease.

\section{Natural history of post-transplant hepatitis B}

In the early era of transplantation, HBV was regarded by many programs as a contraindication to liver transplantation, due to high rates of graft loss due to recurrent HBV disease. Reflecting the effects of immunosuppression on host immune responses and HBV DNA replication, HBV was a rapidly progressive disease post-transplant, with recurrent cirrhosis documented within a substantial proportion within the first 5 years' post-transplant [64]. During this early era, graft survival was only $50 \%$ at 5 years' post-transplant, with the highest risk of graft loss from recurrent $\mathrm{HBV}$ among those who were $\mathrm{HBeAg}$ positive and/or with high HBV DNA levels. A severe form of recurrent HBV, fibrosing cholestatic hepatitis, was seen in $5-10 \%$ of patients and characterized histologically by marked hepatocyte ballooning, a paucity of inflammatory cells and cholestasis [65] and an outcome that was uniformly poor prior to the availability of prophylaxis.

This natural history is now of historical value only, as the risk of recurrent and progressive disease has been eliminated by use of prophylactic therapies. Currently combination HBIG and NA therapy is the standard of care for prevention of HBV infection in many transplant programs. This combination prevents HBV infection in $\searrow 95 \%$ of transplant recipients [66]. Prophylaxis with NA monotherapy using drugs with a low risk of resistance with long-term use, such as ETV or TDF, also is effective [67]. However, there continue to be case reports of patients developing graft loss due to HBV infection, even in the current era of prophylaxis. These cases are related to failure to adhere to prophylaxis, either due to lack of understanding of its importance or cost constraints that led to medication discontinuation. These reports are a reminder of the critical importance of adherence to prophylaxis to insure excellent outcomes. 


\section{HBV prophylaxis in liver transplant recipients}

The ideal outcome of prophylaxis is the prevention of graft reinfection, as evidenced of absence of HBsAg and HBV DNA in serum post-transplant. However, even if reinfection of graft occurs, prevention of HBV disease post-transplant can be assured if HBV suppression is maintained. While many transplant programs use a combination of HBIG and NA therapy, some programs use NA therapy alone. The combination of HBIG plus NA therapy may be better at preventing graft infection, as reflected by presence of HBsAg post-transplant, but both HBIG plus NA and NA alone regimens achieve high success in preventing recurrent disease post-transplant $[67,68]$. Critical to the success of the NA alone prophylaxis strategy is the use of antivirals with a low risk of resistance with long-term use, since treatment will be indefinite. ETV and TDF are the recommended drugs with TDF preferred in patients with prior history of LMV resistance. TDF is the drug most studied in post-transplant patients, but TAF is an alternative and likely to be preferred due its better renal safety profile.

Post-transplant prophylaxis should be individualized (Fig. 2) [69,70]. Prior antiviral drug experience and risk of HBV recurrence, if the selected prophylaxis fails, are key factors in deciding on the prophylaxis strategy. For example, transplant recipients with HDV or HIV coinfection, for whom treatment options may be more limited if prophylaxis fails, may benefit from a combination HBIG plus NA approach. Addition relevant factors include the anticipated patient adherence to prophylactic medications, access to preferred drugs and cost.

The combination of HBIG plus NAs effectively prevents reappearance of HBsAg and HBV DNA in serum and protects the graft from recurrent disease. Efficacy is $>90 \%$ overall, but 95\% if the NA used is TDF or ETV [66]. The dose of HBIG and route of administration vary from study to study. Subcutaneous $[71,72]$ and intramuscular routes of administration are less cumbersome than the intravenous route and achieve similar efficacy in terms of preventing HBV recurrence. Additionally, as the risk of NA resistance has fallen with use of NAs with higher genetic barrier to resistance - TDF and ETV versus LMV - the dose and duration of HBIG use has decreased. Indeed, in some transplant programs, HBIG is given only in the perioperative period [73]. For patients maintained on longterm HBIG plus NA therapy, the optimal trough level of anti-HBs necessary to prevent HBV recurrence is unknown. Recent reports used a trough titer $>100 \mathrm{IU} / \mathrm{L}[72,74]$ but lower levels may be safe if concurrent NA therapy used.

The Hong Kong group has led the way in terms of HBIG-free prophylaxis. In their transplant program, ETV (and more recently TDF) monotherapy is used as prophylaxis, with treatment started on the day of transplant and continued indefinitely. The cumulative rates of HBsAg seroclearance were $85 \%, 88 \%, 87 \%$ and $92 \%$ at year $1,3,5$, and 8 years, respectively and $100 \%$ had undetectable HBV DNA respectively [67]. Thus, this represents an alternative prophylactic strategy and is particularly attractive due to its simplicity and lower overall costs.

A subgroup that warrants a more aggressive effort to prevent HBsAg reappearance is the patient with HDV coinfection, as reemergence of HBsAg (even if HBV DNA suppressed) would lead to active HDV infection, for which few effective therapies exist. Historically, 
prior to the use of prophylactic therapies, HDV patients were shown to have a better prognosis after liver transplantation (LT) than patients with HBV infection alone [75]. This was presumably due to the lower HBV DNA levels present pre-LT in patients with HDV coinfection. However, recurrent HDV infection leading to graft loss does occur and prophylaxis for HBV infection using hepatitis B immune globulin combined with NAs prevents HBV and HDV infections.

Another group of special consideration is the patient with HIV-HBV coinfection. Since 2001, liver transplantation for HIV/HBV coinfected patients with stable HIV disease has been undertaken by several centers in the US and Europe. Post-transplant patient and graft survival have been similar between coinfected and monoinfected patients [76]. The combination of HBIG and NA prophylaxis has been successful in preventing post-transplant HBV recurrence, including patients with detectable HBV DNA at time of transplant. Intermittent detection of low level HBV DNA in prophylaxis with HBIG and NAs, highlights the need for long-term prophylaxis. In the past, many patients had LMV-exposure with resistance, which meant that TDF was the only drug predicted to provide high rates of HBV suppression long-term. Additionally, since TDF resistance, an extremely rare event, was described in a coinfected patient, many experts feel it is prudent to continue HBIG as additional prophylaxis for coinfected patients. However, increasingly, HIV patients are treated with TDF-based antiretroviral therapy as first line therapy (no prior LMV exposure) and since risk of TDF resistance is rare, consideration of post-transplant prophylaxis using TDF monotherapy can be considered, especially in resource-constrained settings.

\section{Post-transplant HBV recurrence}

With the success of modern day HBV prophylaxis, recurrent HBV after transplant is an infrequent occurrence. Overall, less than $5 \%$ of patients are reported to develop recurrence and most cases are managed by use of long-term NA therapy [77]. The exception may be the patient with HDV infection, as NA therapy alone will not change the natural history of HDV recurrence. For these patients, interferon is the only infection-specific therapy and is only modestly effective. Again, this argues strongly for having a high level of vigilance in preventing HDV infection by using dual HBIG plus NA for prophylaxis in this group. For most other patients with $\mathrm{HBV}$ recurrence, there is a need to characterize the reason for treatment failure and to specifically evaluate for HBV resistance variants. Long-term suppressive therapy tailored to the HBV variants is essential. In most cases, TDF/TAF alone or combination nucleoside analogues will be effective.

A unique feature of $\mathrm{HCC}$ recurrence among patients transplanted with $\mathrm{HBV}$, is the presence of HBsAg and HBV DNA in serum as a marker of recurrent HCC [73,78,79] In these cases HBsAg was detectable even in the absence of HBV DNA in the liver or serum in patients with metastatic HCC. It is hypothesized that the source of HBsAg is the metastatic HCC cells, with HBsAg produced from the integrated HBs gene, rather than HBV reinfection of the allograft. Thus, detection of HBsAg in serum in a patient on prophylaxis who has a history of HCC should prompt a search for metastatic disease, especially if HBV DNA is undetectable. 


\section{Acknowledgements}

Dr. Zhou is supported by T32 DK060414 from NIDDK.

\begin{tabular}{ll} 
Abbreviations & \\
ALT & Alanine aminotransferase \\
ARV & Antiretroviral therapy \\
ETV & Entecavir \\
HBV & Hepatitis B virus \\
HBsAg & Hepatitis B surface antigen \\
HBeAg & Hepatitis B e antigen \\
Ant-HBc & Hepatitis B core antibody \\
HDV & Hepatitis D Virus \\
HIV & Human immunodeficiency virus \\
LMV & Lamivudine \\
LT & Liver transplantation \\
NA & Nucleos(t)ide analogues \\
peg-IFN & Peginterferon \\
LdT & Telbivudine \\
TDF & Tenofovir disoproxil fumarate \\
TAF & Tenofovir alafenamide \\
WHO & World Health Organization \\
TNF & Tumor necrosis factor \\
HCC & Hepatocellular carcinoma \\
FTC & Emtricitabine \\
\hline IU & International units \\
\hline &
\end{tabular}

\section{References}

[1]. Beasley RP, Hwang LY, Stevens CE, Lin CC, Hsieh FJ, Wang KY, et al. Efficacy of hepatitis B immune globulin for prevention of perinatal transmission of the hepatitis B virus carrier state: final report of a randomized double-blind, placebo-controlled trial. Hepatology 1983;3(2):13541. [PubMed: 6339349] 
[2]. Yi W, Pan CQ, Hao J, Hu Y, Liu M, Li L, et al. Risk of vertical transmission of hepatitis B after amniocentesis in HBs antigen-positive mothers. J Hepatol 2014;60(3):523-9. [PubMed: 24269471]

[3]. Wiseman E, Fraser M, Holden S, Glass A, Kidson B, Heron L, et al. Perinatal transmission of hepatitis B virus: an Australian experience. Med J Aust 2009;190(9):489-92. [PubMed: 19413519]

[4]. WHO. Guidelines for the prevention, care and treatment of persons with chronic hepatitis B infection 5 12, 2015.

[5]. Giles M, Visvanathan K, Lewin S, Bowden S, Locarnini S, Spelman T, et al. Clinical and virological predictors of hepatic flares in pregnant women with chronic hepatitis B. Gut 2015;64(11):1810-5. [PubMed: 25431458]

[6]. Chang CY, Aziz N, Poongkunran M, Javaid A, Trinh HN, Lau D, et al. Serum alanine aminotransferase and hepatitis B DNA flares in pregnant and postpartum women with chronic hepatitis B. Am J Gastroenterol 2016;111(10): 1410-5. [PubMed: 27456990]

[7]. Kim HY, Choi JY, Park CH, Jang JW, Kim CW, Bae SH, et al. Outcome after discontinuing antiviral agents during pregnancy in women infected with hepatitis B virus. J Clin Virol 2013;56(4):299-305. [PubMed: 23273664]

[8]. Buti M, Gane E, Seto WK, Chan HL, Chuang WL, Stepanova T, et al. Tenofovir alafenamide versus tenofovir disoproxil fumarate for the treatment of patients with $\mathrm{HBeAg}$-negative chronic hepatitis B virus infection: a randomised, double-blind, phase 3, non-inferiority trial. Lancet Gastroenterol Hepatol 2016;1(3):196-206. [PubMed: 28404092]

[9]. Ter Borg MJ, Leemans WF, de Man RA, Janssen HL. Exacerbation of chronic hepatitis B infection after delivery. J Viral Hepat 2008;15(1):37-41. [PubMed: 18088243]

[10]. Elefsiniotis I, Vezali E, Vrachatis D, Hatzianastasiou S, Pappas S, Farmakidis G, et al. Postpartum reactivation of chronic hepatitis $\mathrm{B}$ virus infection among hepatitis $\mathrm{B}$ e-antigen-negative women. World J Gastroenterol 2015;21(4): 1261-7. [PubMed: 25632200]

[11]. Nguyen V, Tan PK, Greenup AJ, Glass A, Davison S, Samarasinghe D, et al. Antiviral therapy for prevention of perinatal HBV transmission: extending therapy beyond birth does not protect against post-partum flare. Aliment Pharmacol Ther 2014;39(10):1225-34. [PubMed: 24666381]

[12]. Terrault NA, Bzowej NH, Chang KM, Hwang JP, Jonas MM, Murad MH, et al. AASLD guidelines for treatment of chronic hepatitis B. Hepatology 2016;63(1):261-83. [PubMed: 26566064]

[13]. http://www.apregistry.com/forms/interim_report.pdf.

[14]. Brown RS Jr, McMahon BJ, Lok AS, Wong JB, Ahmed AT, Mouchli MA, et al. Antiviral therapy in chronic hepatitis B viral infection during pregnancy: a systematic review and meta-analysis. Hepatology 2016;63(1):319-33. [PubMed: 26565396]

[15]. Denneman L, Cohen S, Godfried MH, van Leeuwen E, Nellen JF, Kuijpers TW, et al. In-utero exposure to tenofovir is associated with impaired fetal and infant growth: need for follow-up studies in combination antiretroviral therapy/HIV-exposed infants: author's reply. AIDS 2017;31(4):596-8. [PubMed: 28118236]

[16]. Denneman L, Cohen S, Godfried MH, van Leeuwen E, Nellen JF, Kuijpers TW, et al. In-utero exposure to tenofovir is associated with impaired fetal and infant growth: need for follow-up studies in combination antiretroviral therapy/HIV-exposed infants. AIDS 2016;30(13):2135-7. [PubMed: 27465280]

[17]. Jao J, Abrams EJ, Phillips T, Petro G, Zerbe A, Myer L. Utero tenofovir exposure is not associated with fetal long bone growth. Clin Infect Dis 2016;62(12): 1604-9. [PubMed: 27009251]

[18]. Vigano A, Mora S, Giacomet V, Stucchi S, Manfredini V, Gabiano C, et al. In utero exposure to tenofovir disoproxil fumarate does not impair growth and bone health in HIV-uninfected children born to HIV-infected mothers. Antivir Ther 2011;16(8):1259-66. [PubMed: 22155907]

[19]. Gibb DM, Kizito H, Russell EC, Chidziva E, Zalwango E, Nalumenya R, et al. Pregnancy and infant outcomes among HIV-infected women taking long-term ART with and without tenofovir in the DART trial. PLoS Med 2012;9(5): e1001217. [PubMed: 22615543] 
[20]. Sarin SK, Kumar M, Lau GK, Abbas Z, Chan HL, Chen CJ, et al. Asian-Pacific clinical practice guidelines on the management of hepatitis B: a 2015 update. Hepatol Int 2016;10(1):1-98.

[21]. European Association for the Study of the Liver. Electronic address eee, European Association for the Study of the L. EASL 2017 clinical practice guidelines on the management of hepatitis B virus infection. J Hepatol 2017418 10.1016/j.jhep.2017.03.021. pii: S0168-8278(17)30185-X.

[22]. Chen HL, Lee CN, Chang CH, Ni YH, Shyu MK, Chen SM, et al. Efficacy of maternal tenofovir disoproxil fumarate in interrupting mother-to-infant transmission of hepatitis B virus. Hepatology 2015;62(2):375-86. [PubMed: 25851052]

[23]. Visvanathan K, Dusheiko G, Giles M, Wong ML, Phung N, Walker S, et al. Managing HBV in pregnancy. Prevention, prophylaxis, treatment and followup: position paper produced by Australian, UK and New Zealand key opinion leaders. Gut 2016;65(2):340e50. [PubMed: 26475631]

[24]. Han L, Zhang HW, Xie JX, Zhang Q, Wang HY, Cao GW. A meta-analysis of lamivudine for interruption of mother-to-child transmission of hepatitis B virus. World J Gastroenterol 2011;17(38):4321-33. [PubMed: 22090789]

[25]. Zou H, Chen Y, Duan Z, Zhang H, Pan C. Virologic factors associated with failure to passiveactive immunoprophylaxis in infants born to HBsAgpositive mothers. J Viral Hepat 2012;19(2):e18-25. [PubMed: 22239517]

[26]. Pan CQ, Duan Z, Dai E, Zhang S, Han G, Wang Y, et al. Tenofovir to prevent hepatitis B transmission in mothers with high viral load. N Engl J Med 2016;374(24):2324-34. [PubMed: 27305192]

[27]. Fan L, Owusu-Edusei K Jr, Schillie SF, Murphy TV. Cost-effectiveness of activepassive prophylaxis and antiviral prophylaxis during pregnancy to prevent perinatal hepatitis $\mathrm{B}$ virus infection. Hepatology 2016;63(5):1471-80. [PubMed: 26509655]

[28]. Nayeri UA, Werner EF, Han CS, Pettker CM, Funai EF, Thung SF. Antenatal lamivudine to reduce perinatal hepatitis B transmission: a cost-effectiveness analysis. Am J Obstet Gynecol 2012;207(3)(231):e1-7.

[29]. Pan CQ, Zou HB, Chen Y, Zhang X, Zhang H, Li J, et al. Cesarean section reduces perinatal transmission of hepatitis B virus infection from hepatitis B surface antigen-positive women to their infants. Clin Gastroenterol Hepatol 2013;11(10):1349-55. [PubMed: 23639606]

[30]. Ehrhardt S, Xie C, Guo N, Nelson K, Thio CL. Breastfeeding while taking lamivudine or tenofovir disoproxil fumarate: a review of the evidence. Clin Infect Dis 2015;60(2):275-8. [PubMed: 25313254]

[31]. Corbett AH, Kayira D, White NR, Davis NL, Kourtis AP, Chasela C, et al. Antiretroviral pharmacokinetics in mothers and breastfeeding infants from 6 to 24 weeks post-partum: results of the BAN study. Antivir Ther 2014;19(6):587-95. [PubMed: 24464632]

[32]. Spradling PR, Richardson JT, Buchacz K, Moorman AC, Brooks JT, Investigators HIVOS. Prevalence of chronic hepatitis B virus infection among patients in the HIV Outpatient Study, 1996-2007. J Viral Hepat 2010;17(12): 879-86. [PubMed: 20158604]

[33]. Konopnicki D, Mocroft A, de Wit S, Antunes F, Ledergerber B, Katlama C, et al. Hepatitis B and HIV: prevalence, AIDS progression, response to highly active antiretroviral therapy and increased mortality in the EuroSIDA cohort. AIDS 2005;19(6):593-601. [PubMed: 15802978]

[34]. Thio CL. Hepatitis B and human immunodeficiency virus coinfection. Hepatology 2009;49(5 Suppl):S138-45. [PubMed: 19399813]

[35]. Hoffmann CJ, Thio CL. Clinical implications of HIV and hepatitis B co-infection in Asia and Africa. Lancet Infect Dis 2007;7(6):402-9. [PubMed: 17521593]

[36]. Sun HY, Ko WC, Tsai JJ, Lee HC, Liu CE, Wong WW, et al. Seroprevalence of chronic hepatitis $B$ virus infection among taiwanese human immunodeficiency virus type 1-positive persons in the era of nationwide hepatitis B vaccination. Am J Gastroenterol 2009;104(4):877-84. [PubMed: 19259078]

[37]. Gilson RJ, Hawkins AE, Beecham MR, Ross E, Waite J, Briggs M, et al. Interactions between HIV and hepatitis B virus in homosexual men: effects on the natural history of infection. AIDS 1997;11(5):597-606. [PubMed: 9108941] 
[38]. Sahasrabuddhe VV, Shiels MS, McGlynn KA, Engels EA. The risk of hepatocellular carcinoma among individuals with acquired immunodeficiency syndrome in the United States. Cancer 2012;118(24):6226-33. [PubMed: 22736272]

[39]. Bruix J, Sherman M. Management of hepatocellular carcinoma: an update. Hepatology 2011;53(3):1020-2. [PubMed: 21374666]

[40]. Bica I, McGovern B, Dhar R, Stone D, McGowan K, Scheib R, et al. Increasing mortality due to end-stage liver disease in patients with human immunodeficiency virus infection. Clin Infect Dis 2001;32(3):492-7. [PubMed: 11170959]

[41]. Nikolopoulos GK, Paraskevis D, Hatzitheodorou E, Moschidis Z, Sypsa V, Zavitsanos X, et al. Impact of hepatitis B virus infection on the progression of AIDS and mortality in HIV-infected individuals: a cohort study and metaanalysis. Clin Infect Dis 2009;48(12):1763-71. [PubMed: 19435436]

[42]. Sheng WH, Chen MY, Hsieh SM, Hsiao CF, Wang JT, Hung CC, et al. Impact of chronic hepatitis B virus (HBV) infection on outcomes of patients infected with HIV in an area where HBV infection is hyperendemic. Clin Infect Dis 2004;38(10):1471-7. [PubMed: 15156487]

[43]. Panel on Antiretroviral Guidelines for Adults and Adolescents. Guidelines for the prevention and treatment of opportunistic infections in HIV-infected adults and adolescents: HBV infection 311 2017 Available at: http://aidsinfo.nih.gov/contentfiles/lvguidelines/adult_oi.pdf.

[44]. Panel on Antiretroviral Guidelines for Adults and Adolescents. Guidelines for the use of antiretroviral agents in HIV-1-infected adults and adolescents: Hepatitis B/HIV Coinfection Available at: http://aidsinfo.nih.gov/contentfiles/lvguidelines/AdultandAdolescentGL.pdf.

[45]. Miailhes P, Pradat P, Chevallier M, Lacombe K, Bailly F, Cotte L, et al. Proficiency of transient elastography compared to liver biopsy for the assessment of fibrosis in HIV/HBV-coinfected patients. J Viral Hepat 2011;18(1):61-9. [PubMed: 20196798]

[46]. de Vries-Sluijs TE, Reijnders JG, Hansen BE, Zaaijer HL, Prins JM, Pas SD, et al. Long-term therapy with tenofovir is effective for patients co-infected with human immunodeficiency virus and hepatitis B virus. Gastroenterology 2010;139(6):1934-41. [PubMed: 20801123]

[47]. Nelson M, Portsmouth S, Stebbing J, Atkins M, Barr A, Matthews G, et al. An open-label study of tenofovir in HIV-1 and Hepatitis B virus co-infected individuals. AIDS 2003;17(1):F7-10. [PubMed: 12478090]

[48]. Tourret J, Deray G, Isnard-Bagnis C. Tenofovir effect on the kidneys of HIV-infected patients: a double-edged sword? J Am Soc Nephrol 2013;24(10): 1519-27. [PubMed: 24052632]

[49]. Mills A, Arribas JR, Andrade-Villanueva J, DiPerri G, Van Lunzen J, Koenig E, et al. Switching from tenofovir disoproxil fumarate to tenofovir alafenamide in antiretroviral regimens for virologically suppressed adults with HIV-1 infection: a randomised, active-controlled, multicentre, open-label, phase 3, non-inferiority study. Lancet Infect Dis 2016;16(1):43-52. [PubMed: 26538525]

[50]. McMahon MA, Jilek BL, Brennan TP, Shen L, Zhou Y, Wind-Rotolo M, et al. The HBV drug entecavir - effects on HIV-1 replication and resistance. N Engl J Med 2007;356(25):2614-21. [PubMed: 17582071]

[51]. Di Martino V, Thevenot T, Colin JF, Boyer N, Martinot M, Degos F, et al. Influence of HIV infection on the response to interferon therapy and the longterm outcome of chronic hepatitis $\mathrm{B}$. Gastroenterology 2002;123(6):1812-22. [PubMed: 12454838]

[52]. AIDS NCo, editor. The twin epidemics of substance abuse and HIV; 1991 Washington, DC.

[53]. Matthews GV, Seaberg EC, Avihingsanon A, Bowden S, Dore GJ, Lewin SR, et al. Patterns and causes of suboptimal response to tenofovir-based therapy in individuals coinfected with HIV and hepatitis B virus. Clin Infect Dis 2013;56(9):e87-94. [PubMed: 23315316]

[54]. Kim HN, Rodriguez CV, Van Rompaey S, Eron JJ, Thio CL, Crane HM, et al. Factors associated with delayed hepatitis B viral suppression on tenofovir among patients coinfected with HBV-HIV in the CNICS cohort. J Acquir Immune Defic Syndr 2014;66(1):96-101. [PubMed: 24500175]

[55]. Boyd A, Gozlan J, Maylin S, Delaugerre C, Peytavin G, Girard PM, et al. Persistent viremia in human immunodeficiency virus/hepatitis B coinfected patients undergoing long-term tenofovir: virological and clinical implications. Hepatology 2014;60(2):497-507. [PubMed: 24752996] 
[56]. Sheldon J, Camino N, Rodes B, Bartholomeusz A, Kuiper M, Tacke F, et al. Selection of hepatitis B virus polymerase mutations in HIV-coinfected patients treated with tenofovir. Antivir Ther 2005;10(6):727-34. [PubMed: 16218172]

[57]. Perrillo RP, Gish R, Falck-Ytter YT. American Gastroenterological Association Institute technical review on prevention and treatment of hepatitis $\mathrm{B}$ virus reactivation during immunosuppressive drug therapy. Gastroenterology 2015;148(1):221-244 e3. [PubMed: 25447852]

[58]. Law JK, Ho JK, Hoskins PJ, Erb SR, Steinbrecher UP, Yoshida EM. Fatal reactivation of hepatitis B post-chemotherapy for lymphoma in a hepatitis B surface antigen-negative, hepatitis B core antibody-positive patient: potential implications for future prophylaxis recommendations. Leuk Lymphoma 2005;46(7):1085-9. [PubMed: 16019563]

[59]. Reddy KR, Beavers KL, Hammond SP, Lim JK, Falck-Ytter YT, American Gastroenterological Association I. American Gastroenterological Association Institute guideline on the prevention and treatment of hepatitis B virus reactivation during immunosuppressive drug therapy. Gastroenterology 2015;148(1):215-9. quiz e16-7. [PubMed: 25447850]

[60]. Mozessohn L, Chan KK, Feld JJ, Hicks LK. Hepatitis B reactivation in HBsAgnegative/HBcAbpositive patients receiving rituximab for lymphoma: a meta-analysis. J Viral Hepat 2015;22(10): 842-9. [PubMed: 25765930]

[61]. Perrillo RP, Martin P, Lok AS. Preventing hepatitis B reactivation due to immunosuppressive drug treatments. JAMA 2015;313(16):1617-8. [PubMed: 25790287]

[62]. Burra P, Germani G, Adam R, Karam V, Marzano A, Lampertico P, et al. Liver transplantation for HBV-related cirrhosis in Europe: an ELTR study on evolution and outcomes. J Hepatol 2013;58(2):287-96. [PubMed: 23099188]

[63]. Flemming JA, Kim WR, Brosgart CL, Terrault NA. Reduction in liver transplant wait-listing in the era of direct-acting antiviral therapy. Hepatology 2017;65(3):804-12. [PubMed: 28012259]

[64]. Todo S, Demetris AJ, Van Thiel D, Teperman L, Fung JJ, Starzl TE. Orthotopic liver transplantation for patients with hepatitis B virus-related liver disease. Hepatology 1991;13(4): 619-26. [PubMed: 2010156]

[65]. Davies S, Portmann B, O’Grady J, Aldis P, Chagger K, Alexander G, et al. Hepatic histological findings after transplantation for chronic hepatitis $\mathrm{B}$ virus infection, including a unique pattern of fibrosing cholestatic hepatitis. Hepatology 1991;13:150-7. [PubMed: 1988336]

[66]. Cholongitas E, Papatheodoridis GV. High genetic barrier nucleos(t)ide analogue(s) for prophylaxis from hepatitis B virus recurrence after liver transplantation: a systematic review. Am J Transpl 2013;13(2): 353-62.

[67]. Fung J, Wong T, Chok K, Chan A, Cheung TT, Dai J, et al. Long term outcomes of entecavir monotherapy for chronic hepatitis B after liver transplantation: results up to 8 years. Hepatology 2017331 10.1002/hep.29191 [Epub ahead of print].

[68]. Cholongitas E, Goulis I, Antoniadis N, Fouzas I, Imvrios G, Papanikolaou V, et al. New nucleos $(t)$ ide analogue monoprophylaxis after cessation of hepatitis B immunoglobulin is effective against hepatitis B recurrence. Transpl Int 2014;27(10):1022-8. [PubMed: 24909714]

[69]. Fox AN, Terrault NA. Individualizing hepatitis B infection prophylaxis in liver transplant recipients. J Hepatol 2011;55(3):507-9. [PubMed: 21601598]

[70]. Roche B, Roque-Afonso AM, Nevens F, Samuel D. Rational basis for optimizing short and longterm hepatitis B virus prophylaxis post liver transplantation: role of hepatitis B immune globulin. Transplantation 2015;99(7):1321-34. [PubMed: 26038873]

[71]. De Simone P, Romagnoli R, Tandoi F, Carrai P, Ercolani G, Peri E, et al. Early introduction of subcutaneous hepatitis B immunoglobulin following liver transplantation for hepatitis B virus infection: a prospective, multicenter study. Transplantation 2016;100(7):1507-12. [PubMed: 27023394]

[72]. Klein CG, Cicinnati V, Schmidt H, Ganten T, Scherer MN, Braun F, et al. Compliance and tolerability of subcutaneous hepatitis B immunoglobulin selfadministration in liver transplant patients: a prospective, observational, multicenter study. Ann Transpl 2013;18:677-84. 
[73]. Radhakrishnan K, Chi A, Quan D, Roberts J, Terrault N. Short course of postoperative hepatitis B immunoglobulin plus antivirals prevents reinfection of liver transplant recipients 2017. Transplantation 2017 [in press].

[74]. Idilman R, Akyildiz M, Keskin O, Gungor G, Yilmaz TU, Kalkan C, et al. The long-term efficacy of combining nucleos(t)ide analog and low-dose hepatitis B immunoglobulin on post-transplant hepatitis B virus recurrence. Clin Transpl 2016;30(10):1216-21.

[75]. Samuel D, Muller R, Alexander G, Fassati L, Ducot B, Benhamou J-P, et al. Liver transplantation in European patients with the hepatitis B surface antigen. N Engl J Med 1993;329(25):1842-7. [PubMed: 8247035]

[76]. Coffin CS, Stock PG, Dove LM, Berg CL, Nissen NN, Curry MP, et al. Virologic and clinical outcomes of hepatitis B virus infection in HIV-HBV coinfected transplant recipients. Am J Transpl 2010;10(5):1268-75.

[77]. Coffin CS, Terrault NA. Management of hepatitis B in liver transplant recipients. J Viral Hepat 2007;14(Suppl 1):37-44. [PubMed: 17958641]

[78]. Saab S, Yeganeh M, Nguyen K, Durazo F, Han S, Yersiz H, et al. Recurrence of hepatocellular carcinoma and hepatitis B reinfection in hepatitis B surface antigenpositive patients after liver transplantation. Liver Transpl 2009;15(11):1525-34. [PubMed: 19877207]

[79]. Faria LC, Gigou M, Roque-Afonso AM, Sebagh M, Roche B, Fallot G, et al. Hepatocellular carcinoma is associated with an increased risk of hepatitis B virus recurrence after liver transplantation. Gastroenterology 2008;134(7):1890-9. quiz 2155. [PubMed: 18424269] 


\section{Practice points}

- Tenofovir, telbivudine and lamivudine are drugs recommended in pregnancy, with tenofovir DF preferred due to the low risk for resistance.

- For pregnant women who are not on antiviral therapy, an HBV DNA $>200,000 \mathrm{IU} / \mathrm{mL}$ should prompt antiviral treatment beginning at weeks $28-32$ gestation to reduce the risk of perinatal transmission.

- Breastfeeding is not contraindicated, whether on antiviral therapy or not.

- $\quad$ Post-partum flares are frequent but rarely are severe or require treatment. 


\section{Practice points}

- $\quad$ All HIV patients with HBV coinfection should be treated with antiretroviral therapy that include tenofovir plus emtricitabine or lamivudine.

- Entecavir is an alternative HBV therapy for those on a fully suppressive ARV regimen; the 1-mg dose is recommended if prior lamivudine exposure.

- Treatment interruptions should be avoided; with close monitoring of HBV DNA and ALT until treatment resumes.

- TAF rather than TDF should be considered in those with or at risk for renal or bone toxicities. 


\section{Practice points}

- At risk patients receiving chemotherapy, immunosuppressives or diseasemodifying drugs should be tested for $\mathrm{HBsAg}$, anti-HBc and anti-HBs

- $\quad$ Antiviral prophylaxis with ETV, TDF and TAF is indicated for HBsAg positive and $\mathrm{HBsAg}$-negative/anti-HBc positive patients with moderate to high risk $(>1 \%)$ of $\mathrm{HBV}$ reactivation

- $\quad$ Antiviral prophylaxis should be started concurrent with or before immunosuppressive therapy and continue until 6-12 months post-treatment.

- $\quad$ For patients at low risk of reactivation, monitoring of HBV DNA (and HBsAg if $\mathrm{HBsAg}$ negative at baseline) is the preferred strategy with antiviral therapy given on demand if evidence of $\mathrm{HBV}$ reactivation. 


\section{Practice points}

- $\quad$ Patients with chronic hepatitis B have excellent outcomes post-transplant due to the high efficacy of therapies to prevent and suppress recurrent HBV infection in the graft.

- Hepatitis B immunoglobulin plus low dose NA therapy is highly effective in preventing HBV reinfection across a broad spectrum of patients, including those with HDV and HIV coinfection.

- $\quad$ NA monotherapy using ETV, TDF or TAF is effective in preventing HBV graft loss from recurrent $\mathrm{HBV}$ and is a cost-effective option for patients at low risk for recurrence.

- $\quad$ Liver transplant recipients require life-long therapy. 


\section{Research agenda}

- $\quad$ Studies are needed to establish the safety and efficacy of tenofovir alafenamide in pregnancy.

- The prevalence and long-term clinical consequences, if any, of intermittent low-level HBV viremia in patients with HIV-HBV coinfection on tenofovirbased antiretroviral therapy needs to be elucidated.

- $\quad$ More research of HBsAg-positive and HBsAg-negative/anti-HBc positive patients receiving immunosuppressant drugs in the moderate risk group (1$10 \%$ risk) for reactivation is needed to better define risk by drug class and to determine whether monitoring and on-demand antiviral therapy rather than antiviral prophylaxis may be an alternative management approach for some drugs.

- Better virologic and immunologic tools are needed to identify the posttransplant patients who have completely cleared HBV infection and who may be potential candidates for complete withdrawal of anti-HBV prophylaxis. 


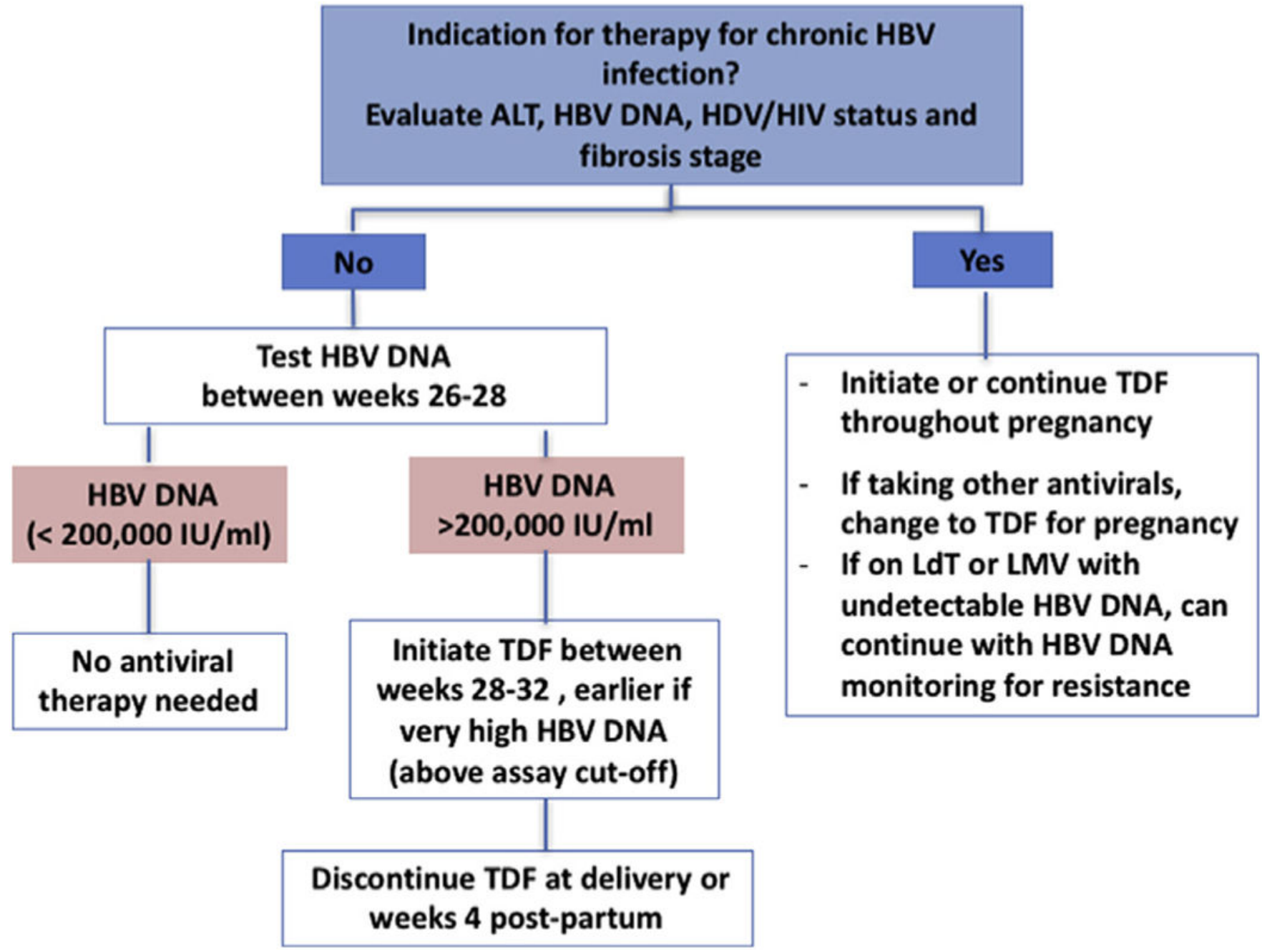

Fig. 1. Management algorithm of chronic HBV infection during pregnancy.

Initial assessment requires a determination of the need for treatment of chronic HBV, independent of pregnancy. This will determine the need for treatment during pregnancy and after delivery. For women without active or advanced chronic HBV infection, antiviral therapy can be deferred until post-partum. However, all women need to be assessed in the second trimester for consideration of antiviral therapy for prevention of mother-to-child transmission. Women with HBV DNA above 200,000 IU/mL warrant antiviral therapy with tenofovir, telbivudine or lamivudine in the third trimester. Tenofovir is the preferred drug during pregnancy. 


\section{Patient Factors Influencing Choices of Prophylactic Therapy}
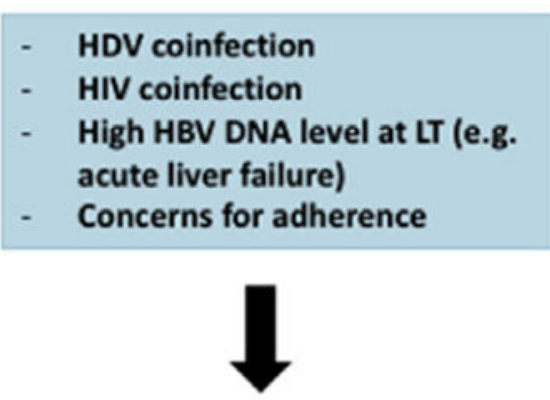

NA plus Long-Term HBIG
HBV DNA $<100 \mathrm{IU} / \mathrm{mL}$ at LT

- HDV negative

- HIV negative

* Perioperative to $\leq 6$ months

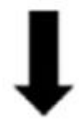

ETV, TDF, or TAF plus Short-Term HBIG*
- HBV DNA undetectable at LT HDV negative

- HIV negative HBIG unavailable or cost prohibitive

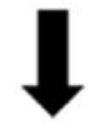

ETV, TDF or TAF without

HBIG

\section{Prophylactic Therapy Options Post Liver Transplantation}

Fig. 2. Factors to consider for individualization of $\mathrm{HBV}$ prophylaxis in liver transplant recipients.

Prophylaxis can be individualized with patients at low risk for recurrent HBV treated without HBIG or with short duration HBIG. Other important factors to consider include HBIG availability and cost, presence of coinfections (HDV and HIV) and adherence.* Short term HBIG varies from 5 days to 6 months. 


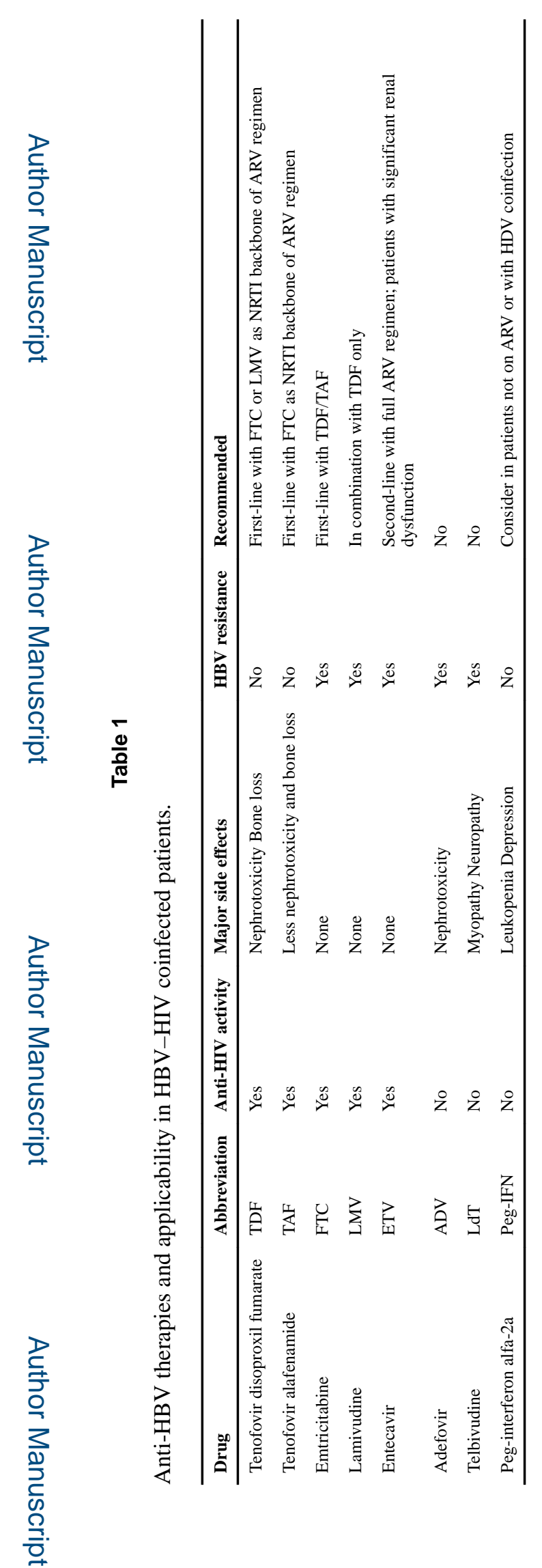

Best Pract Res Clin Gastroenterol. Author manuscript; available in PMC 2019 June 05. 


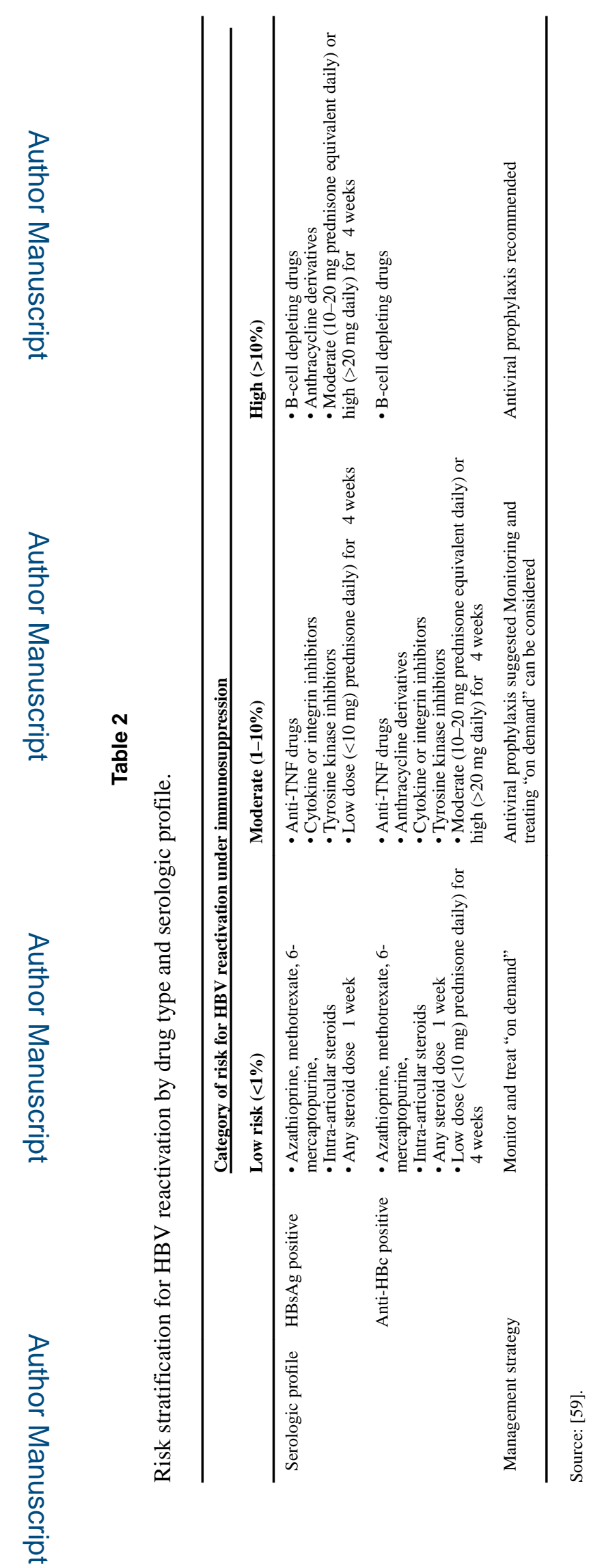

Best Pract Res Clin Gastroenterol. Author manuscript; available in PMC 2019 June 05. 